\title{
Somatic embryogenesis and in vitro plant regeneration from various explants of the halophyte Leymus chinensis (Trin.)
}

\author{
Yan Lin Sun - Soon-Kwan Hong
}

Received: 21 July 2009 / Accepted: 19 August 2009

(c) Korean Society for Plant Biotechnology

\begin{abstract}
The halophyte Leymus chinensis (Trin.) is a perennial rhizome grass (tribe Gramineae) that is widely distributed throughout China, Mongolia and Siberia. This study was conducted to investigate an optimal condition for plant regeneration from mature seeds, leaf base segments, and root segments in L. chinensis. Plant growth regulators affecting embryogenic callus induction and plant regeneration were investigated by four-factor-three-level $\left[\mathrm{L}_{9}\left(3^{4}\right)\right]$ orthogonal test in this study. The effects of explants types (mature seeds, leaf base segments and root segments), callus types, medium types were examined in this study. Wild type (WT) and Jisheng No. 1 plants (JS) were used for primary callus induction. A clear explants difference was seen during callus induction; mature seeds were considered as the preferred explants; and the highest frequency of callus induction was obtained in Medium 6 using mature seeds as explants in WT. Plant regeneration ability was evaluated by frequencies of green callus forming, shooting, rooting, and shooting with roots. Effect of a-naphthalene acetic acid (NAA) on shoot regeneration was remarkable with the highest frequency of $70.8 \%$ in WT after 2-month culture. The medium with 0.2 $0.5 \mathrm{mg} / \mathrm{L}$ NAA was found to have the highest shoot induction. All regenerated shoots were successfully rooted when transferred on half-strength Murashige and Skoog (MS) basal medium. The acclimatized plantlets were grown to mature with flowering and seeds setting in green house conditions.
\end{abstract}

Y. L. Sun · S.-K. Hong $(\bowtie)$

Department of Plant Biotechnology, Division of Biotechnology,

College of Biotechnology, Kangwon National University,

Chuncheon, Kangwon-Do, 200-701, Korea

e-mail: soonkwan@kangwon.ac.kr

S.-K. Hong

Institute of Bioscience and Biotechnology, Kangwon National

University, Chuncheon, Kangwon-Do, 200-701, Korea
Keywords Leymus chinensis, Callus induction, Plant regeneration, Somatic embryogenesis, Proline, Glycine

Abbreviations
$\begin{array}{ll}\mathrm{L}_{9}\left(3^{4}\right) & \text { Four-factor-three-level } \\ \text { WT } & \text { Wild-type plants } \\ \text { JS } & \text { Jisheng No.1 plants } \\ \text { NAA } & \text { a-Naphthalene acetic acid } \\ \text { 2,4-D } & \text { 2,4-Dichlorophenoxyacetic acid } \\ \text { MS } & \text { Murashige and Skoog } \\ \text { IP } & \text { Imperfect } \\ \text { M } & \text { Moderate } \\ \text { P } & \text { Perfect } \\ \text { Kn } & \text { Kinetin } \\ \text { PAT } & \text { Phosphinothricin acetyltransferase } \\ \text { LEA } & \text { Late embryogenesis abundant }\end{array}$

\section{Introduction}

The halophyte Leymus chinensis (Trin.) Tzvel. is a perennial rhizome grass of the tribe Gramineae that is widely distributed throughout northern China, Mongolia and Siberia (Huang et al. 2004). Because of its intrinsically high saline-alkaline tolerance (Jin et al. 2006), L. chinensis is used as a soilbinding plant to protect soil from desertification. Due to its high vegetative productivity, protein content, and nourishment to cattle, $L$. chinensis is also cultivated as a major grass forage product. Under the pressure of environmental stress and grassland degradation caused by men and animals (Zhang et al. 2002), its low sexual reproductivity (Huang et al. 2004) and relatively drought-sensitivity (Bai et al. 2004), the great demands for physiological traits of $L$. chinensis require more 
rapid improvement of this grass.

To improve traits of this grass, several investigations have been conducted (Wang 1998), including expression profiling of the salt-related genes ( Jin et al. 2008), nitrous oxide $\left(\mathrm{N}_{2} \mathrm{O}\right)$ emission from and methane $\left(\mathrm{CH}_{4}\right)$ uptake under environmental stresses (Wang et al. 2005), effect of soil moisture on gas exchange (Xu et al. 2005) and in vitro tissue culture (Liu et al. 2004, Kim et al. 2005). Until now, the phosphinothricin acetyltransferase (PAT) gene has been transformed to $L$. chinensis through microprojectile bombardment (Shu et al. 2005). Recent studies reported that a wheat late embryogenesis abundant (LEA) gene, TaLEA3 gene had been transferred into L. chinensis via Agrobacterium-mediated transformation (Wang et al. 2008). However, little effort has been made to study a highly efficient plant regeneration system of $L$. chinensis.

For L. chinensis, it was known that Gao (1982) reported tissue culture using rhizome as explants with $24.4 \%$ callus induction frequency. Later, Liu et al. (2002) found that immature stachys-derived callus differentiated successfully into regenerated plants, but with low plant regeneration frequency. Until now, an efficient regeneration system via in vitro culture of immature inflorescences of $L$. chinensis with $90.29 \%$ callus induction frequency and $48.58 \%$ plant regeneration frequency (Liu et al. 2004) were widely used for transformation system (Shu et al. 2005, Wang et al. 2008). Due to the localization of explants in existing tissue culture system, demands for various explants-derived, rapid and efficient plant regeneration systems of this grass have therefore become urgent.

This study established an efficient callus induction system of L. chinensis with high plant regeneration frequency, which depended on explants source, the proportion of amino acids, growth hormones and organic nitric salt. Somatic embryogenesis derived from mature seeds is reported to have several advantages, such as convenient acquisition and easy conservation in bulk quantities (Huang and Wei 2004). Leaves and roots used in this work were convenient to obtain from sterile seedlings from mature seeds. The concentrations of amino acids (glycine and proline), hormones [2,4-dichlorophenoxyacetic acid (2,4-D)], and organic nitric salt [potassium nitrate $\left(\mathrm{KNO}_{3}\right)$ ] were studied on modulating preferred callus induction medium by $\mathrm{L}_{9}\left(3^{4}\right)$ orthogonal test. The frequency of callus induction integrated with callus type and relevant callus formation was conducted and considered as criterion of ability of callus formation. The frequencies of green callus forming, shooting, rooting firstly, and shooting with roots in different stages of plant regeneration were evaluated. So, this study was executed to investigate an optimal condition for plant regeneration and search for a simplified approach of scale of the ability of plant regeneration.

\section{Materials and methods}

Plant materials

Mature seeds of wild-type plants (WT) of $L$. chinensis were collected in 2007 at the grassland in Siping, Jilin province in China; this genotype has kept relatively constant in physiological traits due to many years of natural evolution. Mature seeds of Jisheng No. 1 plants (JS) of $L$. chinensis were brought in 2008 in Changchun Yangcao seeds station, Jilin province in China; this genotype were cultivated as a new variety with high tolerance and vegetative productivity. All seeds were storage at $4^{\circ} \mathrm{C}$.

Preparation of various explants

All mature seeds were de-husked and surface-sterilized with $70 \%$ ethanol (v/v in water) $1 \mathrm{~min}$, and then $5 \%$ sodium hypochlorite ( $\mathrm{w} / \mathrm{v}$ in water) $20 \mathrm{~min}$, according to the Liu et al. (2002) method. The sterilized seeds were rinsed five times with sterile water, and separated into two parts. One part of surface-sterilized seeds was used for direct callus induction with cultures at $28 \pm 2^{\circ} \mathrm{C}$ in dark and the other part was germinated on Murashige and Skoog (MS) medium(Murashige and Skoog 1962) for supplying seedling explants, with cultures at $28 \pm 2{ }^{\circ} \mathrm{C}$ in a $16 / 8 \mathrm{~h}$ (light/dark) photoperiod. After germination, leaf base parts and roots from seedlings were cut into $1 \mathrm{~cm}$ segments, and used for callus induction. Cultures were maintained at $28 \pm 2^{\circ} \mathrm{C}$ in a $16 / 8 \mathrm{~h}$ (light/dark) photoperiod. Ten explants (mature seeds, leaf base segments and root segments) were plated for each $90 \times 15 \mathrm{~mm}$ petri dish; 85-100 explants were used for each replicate; three times of replicate were performed for each experiment.

Callus induction medium by $\mathrm{L}_{9}\left(3^{4}\right)$ orthogonal test

Two types of amino acid, glycine (1.0, 2.0 and $4.0 \mathrm{mg} / \mathrm{L})$ and proline $(0.3,0.5$ and $1.0 \mathrm{mg} / \mathrm{L})$, hormone, $2,4-\mathrm{D}(0.5,1.0$ and $2.0 \mathrm{mg} / \mathrm{L})$ and organic nitric salt, $\mathrm{KNO}_{3}(0.5,1.0$ and $2.0 \mathrm{~g} / \mathrm{L})$ were studied as four factors (with three levels) in $\mathrm{L}_{9}\left(3^{4}\right)$ orthogonal test (Table 1). In this experiment, callus induction medium contained MS medium supplemented with $30.0 \mathrm{~g} / \mathrm{L}$ sucrose and $4.0 \mathrm{~g} / \mathrm{L}$ Gelrite for solidification, and different proportion of glycine, proline, 2,4-D and $\mathrm{KNO}_{3}$. The $\mathrm{pH}$ was adjusted to 5.8 by $0.1 \mathrm{~N} \mathrm{NaOH}$ prior to the addition of Gelrite. Media were sterilized by autoclaving at $120^{\circ} \mathrm{C}$ and $1.4 \mathrm{Kg} / \mathrm{cm}^{2}$ for $20 \mathrm{~min}$. 
Table 1 Medium 1 to 9 components by $L_{9}\left(3^{4}\right)$ orthogonal test

\begin{tabular}{|c|c|c|c|c|c|c|c|c|c|c|c|c|}
\hline \multirow{2}{*}{ Medium $^{1}$} & $2,4-\mathrm{D}$ & $(\mathrm{mg} / \mathrm{L})$ & & Glycine & $(\mathrm{mg} / \mathrm{L})$ & & Proline & $(\mathrm{g} / \mathrm{L})$ & & $\mathrm{KNO}_{3}$ & $(\mathrm{~g} / \mathrm{L})$ & \\
\hline & 0.5 & 1.0 & 2.0 & 1.0 & 2.0 & 4.0 & 0.3 & 0.5 & 1.0 & 0.5 & 1.0 & 2.0 \\
\hline 1 & $*$ & & & $*$ & & & $*$ & & & $*$ & & \\
\hline 2 & $*$ & & & & $*$ & & & * & & & $*$ & \\
\hline 3 & $*$ & & & & & $*$ & & & $*$ & & & $*$ \\
\hline 4 & & $*$ & & * & & & & * & & & & $*$ \\
\hline 5 & & $*$ & & & $*$ & & & & * & $*$ & & \\
\hline 6 & & $*$ & & & & $*$ & $*$ & & & & * & \\
\hline 7 & & & $*$ & $*$ & & & & & $*$ & & $*$ & \\
\hline 8 & & & $*$ & & $*$ & & $*$ & & & & & $*$ \\
\hline 9 & & & $*$ & & & $*$ & & $*$ & & $*$ & & \\
\hline
\end{tabular}

${ }^{1}$ Media were MS medium supplemented with a combination of 2,4-D, glycine, proline and $\mathrm{KNO}_{3}$

Callus induction

Explants were incubated for callus induction on media by $\mathrm{L}_{9}\left(3^{4}\right)$ orthogonal test at $28 \pm 2{ }^{\circ} \mathrm{C}$ in dark with biweekly subculture. After 2-month culture, callus types were evaluated as imperfect (IP, cotton-like, watery or translucent callus, nearly non-growth), moderate ( $\mathrm{M}$, friable, soft, white callus, slow growth) and perfect (P, stout, yellow or creamy white callus, fast growth). Meanwhile, the frequency of callus induction was calculated as the ratio of the number of explants producing calli to the total number of explants plated on callus induction medium; the frequency of each type of callus was calculated as the ratio of the number of explants producing relevant type of calli to the number of explants producing calli.

Plant regeneration

After primary callus induction, only type $\mathrm{P}$ callus was selected for plant regeneration. The calli were transferred onto regeneration medium containing MS medium with 2.0 $\mathrm{mg} / \mathrm{L}$ kinetin $(\mathrm{Kn})$, various concentrations of a-naphthalene acetic acid (NAA, $0,0.2,0.5,1.0$ or $1.5 \mathrm{mg} / \mathrm{L}$ ) in the presence or absence of casamino acid $(2.0 \mathrm{~g} / \mathrm{L})$. The $\mathrm{pH}$ was adjusted to 5.8 by $0.1 \mathrm{~N} \mathrm{NaOH}$ prior to autoclaving. Cultures were incubated at $28 \pm 2^{\circ} \mathrm{C}$ in a $16 / 8 \mathrm{~h}$ (light/dark) photoperiod under low light conditions $\left(25 \mu \mathrm{E} \mathrm{m}^{-2} \mathrm{~s}^{-1}\right)$ for 1 week, and then maintained under high light conditions $\left(70 \mu \mathrm{E} \mathrm{m}^{-2} \mathrm{~s}^{-1}\right)$ with biweekly subculture. After 2-month culture, the frequency of plant regeneration was calculated as the ratio of the number of calli regenerating shoots to the total number of calli plated on regeneration medium. In addition, the frequency of green callus forming was evaluated as the ratio of the number of calli producing green blots to the number of calli plated on regeneration medium; the frequency of shooting was evaluated as the ratio of the number of calli producing shoots to the number of calli plated on regeneration medium; the frequency of rooting was evaluated as the ratio of the number of calli regenerating roots only to the number of calli plated on regeneration medium; the frequency of shooting with roots were evaluated as the ratio of the number of calli regenerating shoots and roots to the number of calli plated on regeneration medium. Ten calli were plated for each $90 \times 15 \mathrm{~mm}$ petri dish; $85-100$ calli were used for each replicate; three times of replicate were performed for each experiment.

\section{Rooting}

Regenerated shoots were transferred onto half-strength MS medium for root development ( 1 callus with regenerated shoots for each $90 \times 15 \mathrm{~mm}$ petri dish) until regenerated shoots grown to $3 \mathrm{~cm}$ in length. The $\mathrm{pH}$ was adjusted to 5.8 by $1.0 \mathrm{~N} \mathrm{NaOH}$ prior to autoclaving. Cultures were incubated at $28 \pm 2^{\circ} \mathrm{C}$ in a $16 / 8 \mathrm{~h}$ (light/dark) photoperiod under high light conditions $\left(70 \mu \mathrm{E} \mathrm{m}^{-2} \mathrm{~s}^{-1}\right)$. Well-rooted plantlets were removed from culture medium, removed the media with sterile water, and then transplanted into a mixture of sterilized soil and vermiculite $(3 / 1, v / v)$ in the greenhouse.

\section{Statistical analysis}

All statistically significant differences among means were determined by two-way analysis of variance (ANOVA) using Duncan's multiple-range test (Duncan 1955). $P$ value of less than 0.05 was considered as significant. 


\section{Results}

Primary callus induction from mature seeds, leaf base segments and root segments

Explants cultured on MS medium containing different proportion of glycine, proline, 2,4-D and $\mathrm{KNO}_{3}$ (Table 1) could produce primary callus within 2 weeks (Fig. 1A, B, C). When leaves from sterile seedlings used as explants, calli could only be induced form the base part adjacent to seed (Fig. 1B) but not the other part. Root segments produced primary calli easily, but the growth status of callus was commonly watery and translucent (Fig. 1C), which was not used for shoot regeneration. Primary callus was proliferated with a biweekly subculture (Fig. 1D, E, F), however, results indicated that callus formation and callus proliferation rate largely depended on medium type and callus type.

The frequencies of mature seeds-, leaf base segments- and root segments-derived primary callus induction were variable in responses to $\mathrm{L}_{9}\left(3^{4}\right)$ orthogonal test but with no variation of explants, while there were significant differences between WT and JS on the same medium (Fig. 2). For WT callus induction, the highest frequencies of callus induction from mature seeds, leaf base segments and root segments were obtained on Medium 6, Medium 6 and 2, respectively. Combined with the responses of callus induction from various explants on the same medium, a significant decrease of the frequency of WT callus induction was obtained on Medium 4 when mature seeds used as explants (Fig. 2). And a sig-

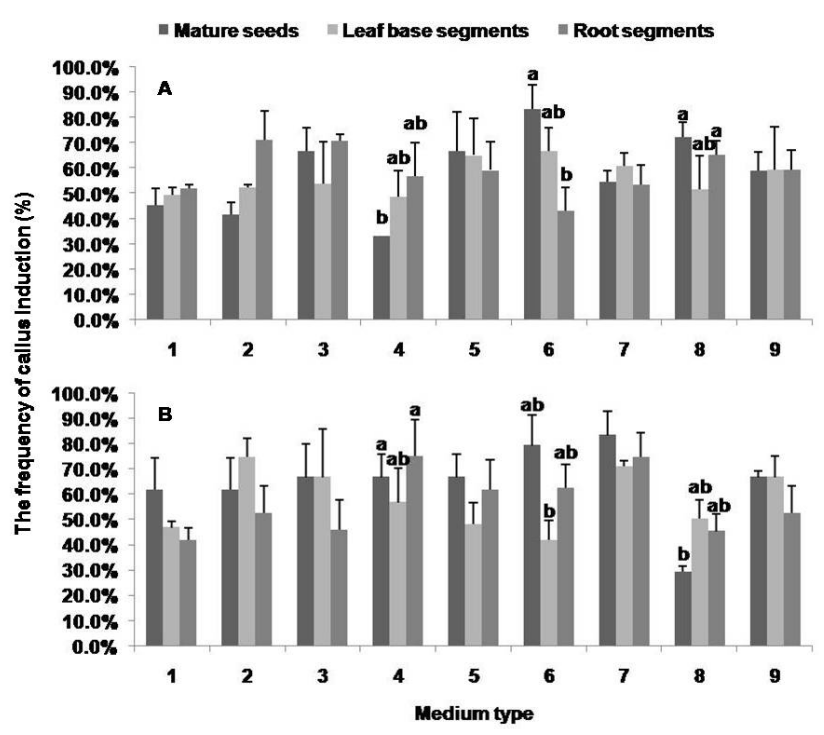

Fig. 2 The frequency of callus induction (\%) derived from mature seeds, leaf base segments and root segments of WT (A) and JS (B). Values are the mean of 3 repeated experiments. In each experiment, 85-100 explants were tested. Means followed by the same letter in the same medium are not significantly different at $P<0.05$ according to two-way ANOVA using Duncan's multiple -range test. The frequency of callus induction was evaluated by the ratio of the number of explants regenerating calli to the total number of explants plated on callus induction medium after 2-month culture
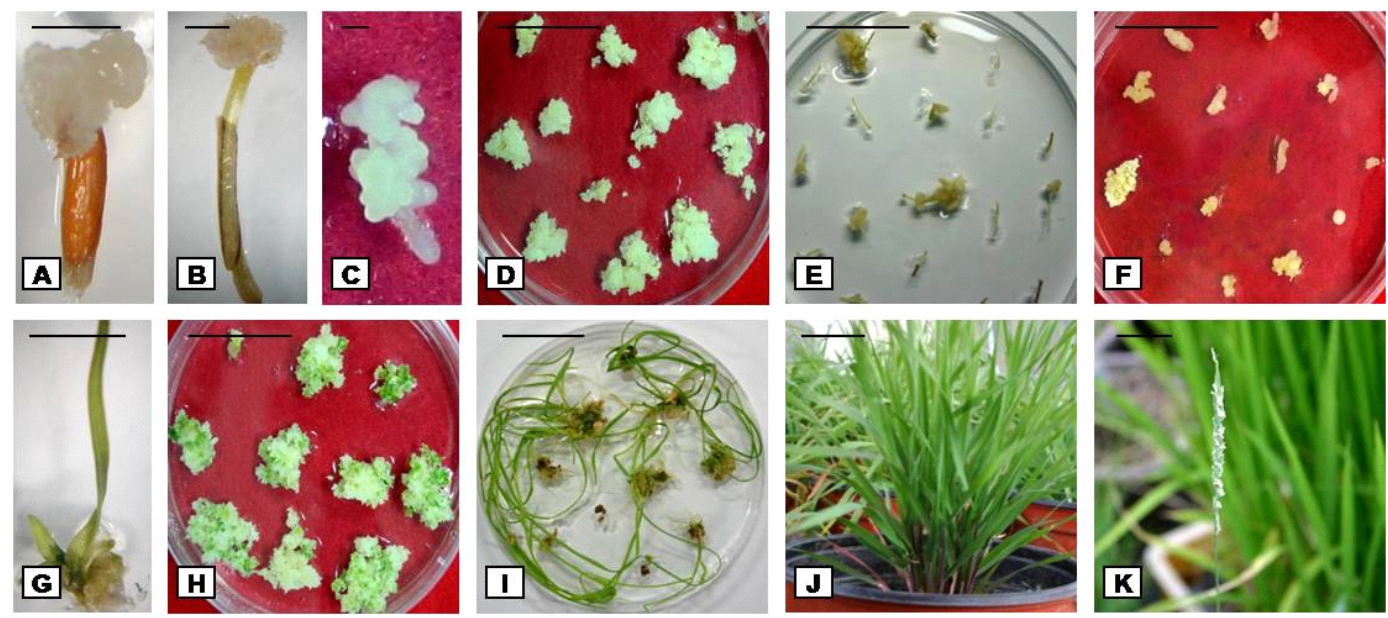

Fig. 1 Primary callus induction and plant regeneration derived from mature seeds, leaf base segments and root segments of $L$. chinensis. A. Primary callus derived from a mature seed with 2-week culture on callus induction medium; B. Primary callus derived from a leaf base segment with 2-week culture on callus induction medium; C. Primary callus derived from a root segment with 2-week culture on callus induction medium; D. Primary calli derived from mature seeds after 2-month culture on callus induction medium; E. Primary calli derived from leaf base segments after 2-month culture on callus induction medium; F. Primary calli derived from root segments after 2-month culture on callus induction medium; G. Embryogenic callus with regenerated shoots after 2-month culture on plant regeneration medium; H. Multiple shoots induced from embryogenic callus after 2-month culture on MS medium supplemented with $0.2 \mathrm{mg} / \mathrm{L} \mathrm{NAA}, 2.0 \mathrm{mg} / \mathrm{L} \mathrm{Kn}$ and $2.0 \mathrm{~g} / \mathrm{L}$ casamino acid; I. Roots induced from shoots with transferred on half-strength MS medium within the next following one week; J. Regenerated plant grown in a pot with a mixture of sterilized soil and vermiculite (3/1) in the greenhouse for 3 months; K. Flowering of regenerated plant. Scale bars represent $2 \mathrm{~mm}(\mathrm{~A}, \mathrm{~B}, \mathrm{C}), 10 \mathrm{~mm}(\mathrm{G})$ and $25 \mathrm{~mm}(\mathrm{D}, \mathrm{E}$, $\mathrm{F}, \mathrm{H}, \mathrm{I}, \mathrm{J}, \mathrm{K})$ 

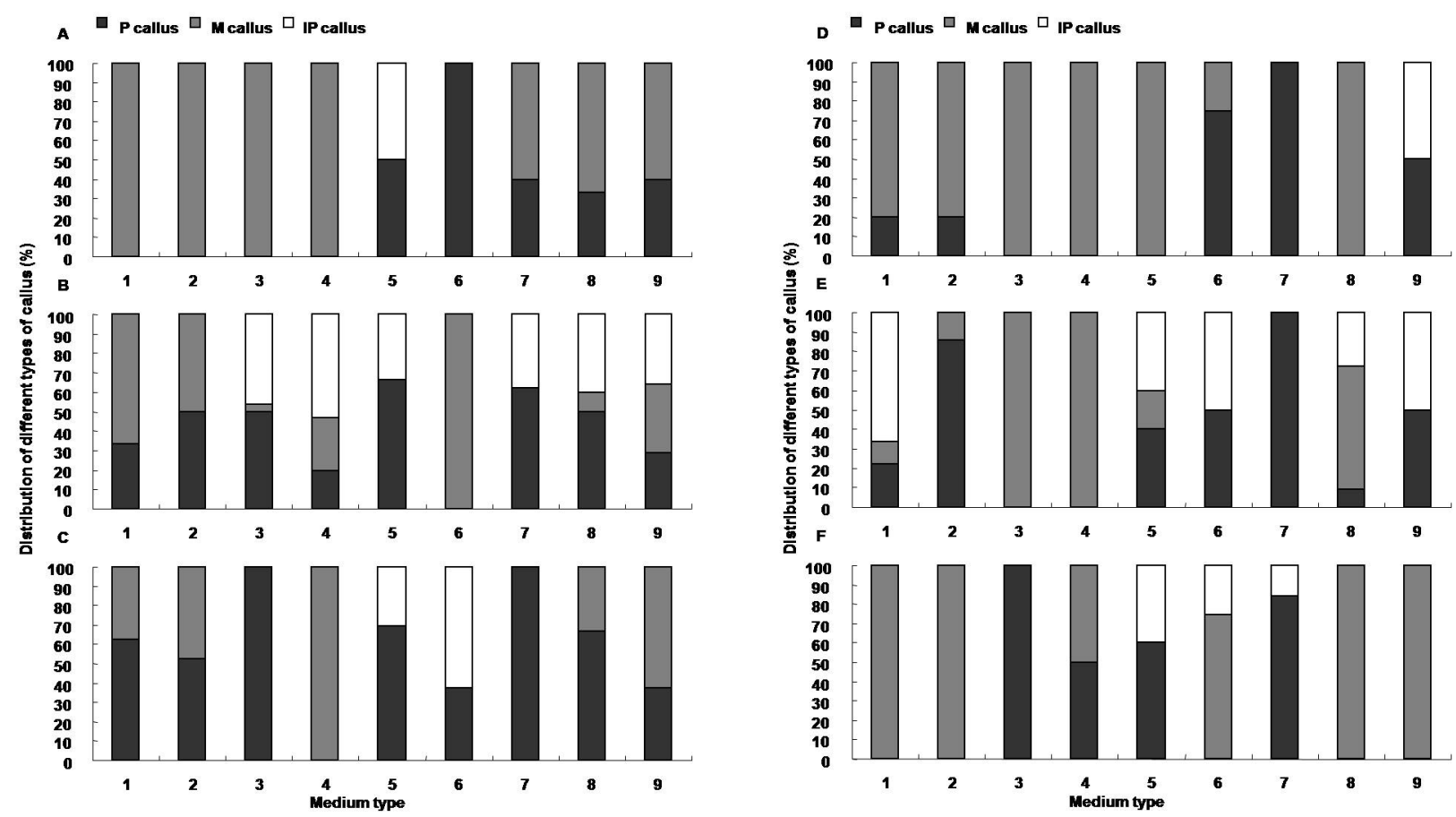

Fig. 3 Distribution of different types of calli (\%) derived from mature seeds (A and D), leaf base segments (B and E) and root segments (C and F) of both genotypes (WT and JS, respectively). Primary calli were divided into three types: perfect (P) callus, which is stout, yellow or creamy white and grow fast; moderate (M) callus, which is friable, soft, white and grow slowly; and imperfect (IP) callus, which is cotton-like, watery or translucent and has nearly non-growth. Values are the mean of 3 repeated experiments. In each experiment, 85-100 explants were tested. The frequency of different types of callus induction was evaluated after 2-month culture on callus induction medium

nificant decline of WT callus induction was also found on Medium 6 using root segments as explants. The frequency of root segments-derived callus induction was significantly lower than that of mature seeds-derived callus induction on Medium 6, indicating that callus induction of this grass was explants-related. Mature seeds of JS showed the highest frequency of callus induction on Medium 7; leaf base segments and root segments of JS showed the highest ability of callus induction on Medium 2 and 4, respectively. Due to the clear explants-related difference, leaf base segments used as explants showed significant decrease in callus induction on Medium 6, and mature seeds showed few declines in callus induction on Medium 8. Likewise, a clear genotypes-related difference was obtained from mature seeds-derived callus induction on Medium 4 and 8.

To evaluate the ability of callus induction, primary calli were divided into three types: perfect (P, stout, yellow or creamy white callus, fast growth), moderate ( $\mathrm{M}$, friable, soft, white callus, slow growth) and imperfect (IP, cotton-like, watery or translucent callus, nearly non-growth) callus. Distribution of different types of calli was investigated after 2-month culture on callus induction medium (Fig. 3). Among three types of calli, the proportion of IP callus which could not be induced regenerated shoots highly affected the ability of callus induction. Medium 6 enhanced the ability of mature seeds-derived callus induction, especially in WT (Fig. 3A). JS callus induction showed better responses to Medium 7 compared with responses to Medium 6, having relatively low proportion of IP callus (Fig. 3D, E, F). However, the proportion of IP callus derived from leaf base segments and root segments was generally higher than that from mature seeds.

Based on these results, mature seeds were considered as the preferred explants and Medium 6 and 7 were selected for the optimal medium of callus induction of WT and JS, respectively.

\section{Plant regeneration}

It is known that the ability of shoot regeneration has a close relation with callus growth status, so in this study, only type $\mathrm{P}$ callus derived from various explants was used for shoot regeneration. After 2-month culture on callus induction medium, P calli were transferred on MS medium supplemented with various concentrations of NAA $(0,0.2,0.5,1.0$ or 1.5 $\mathrm{mg} / \mathrm{L}$ ) in combination with $2.0 \mathrm{mg} / \mathrm{L} \mathrm{Kn}$ and $2.0 \mathrm{~g} / \mathrm{L}$ casamino acid. After 2-month culture on plant regeneration medium, most primary calli had rapid growth rates and produced 
Table 2 The frequency of plant regeneration of WT and JS in MS medium supplemented with various concentrations of NAA (0, $0.2,0.5,1.0$ or $1.5 \mathrm{mg} / \mathrm{L}), 2.0 \mathrm{mg} / \mathrm{L} \mathrm{Kn}$ and $2.0 \mathrm{~g} / \mathrm{L}$ casamino acid

\begin{tabular}{ccc}
\hline $\begin{array}{c}\text { Concentration of NAA } \\
(\mathrm{mg} / \mathrm{L})\end{array}$ & \multicolumn{2}{c}{ The frequency of plant regeneration } \\
\cline { 2 - 3 } & WT & $11.2 \pm 0.6^{\mathrm{A}}$ \\
\hline 0.0 & $23.0 \pm 1.0^{\mathrm{A}}$ & $68.1 \pm 0.5^{\mathrm{C}}$ \\
0.2 & $70.8 \pm 1.0^{\mathrm{B}}$ & $44.6 \pm 0.3^{\mathrm{B}}$ \\
1.0 & $53.7 \pm 1.2^{\mathrm{B}}$ & $18.3 \pm 0.5^{\mathrm{A}}$ \\
1.5 & $28.8 \pm 0.8^{\mathrm{A}}$ & $41.1 \pm 0.8^{\mathrm{B}}$ \\
\hline
\end{tabular}

\footnotetext{
${ }^{1}$ Values are the mean of 3 repeated experiments. In each experiment, 85-100 embryogenic calli were tested. Means followed by the same letter in the same column are not significantly different at $P<0.05$ according to two-way ANOVA using Duncan's multiplerange test. The frequency of plant regeneration was evaluated by the ratio of the number of calli regenerating shoots to the total number of calli plated on plant regeneration medium after 2-month culture
}

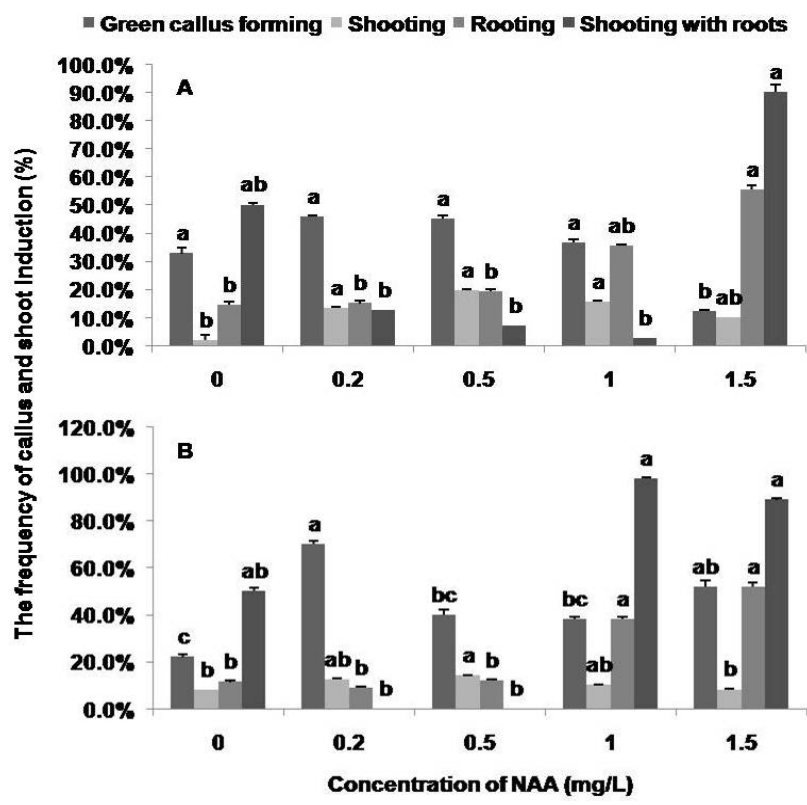

Fig. 4 The frequency of callus and shoot induction (\%) in MS medium supplemented with various concentrations of NAA $(0,0.2$, $0.5,1.0$ or $1.5 \mathrm{mg} / \mathrm{L}), 2.0 \mathrm{mg} / \mathrm{L} \mathrm{Kn}$ and $2.0 \mathrm{~g} / \mathrm{L}$ casamino acid of WT (A) and JS (B). Values are the mean of 3 repeated experiments. In each experiment, 85-100 embryogenic calli were tested. Means followed by the same letter in the same series are not significantly different at $P<0.05$ according to two-way ANOVA using Duncan's multiple-range test. The frequency of callus and shoot induction was evaluated after 2-month culture on plant regeneration medium

green blots (Fig. 1G, H). From $11.2 \%$ to $70.8 \%$ of primary calli developed into shoots or plantlets on relevant plant regeneration medium after 2-month culture (Table 2). The shoot regeneration ability was strongly influenced by various concentrations of NAA, but not genotypes. The frequency of plant regeneration had a significantly increase in MS medium supplemented with $0.2-0.5 \mathrm{mg} / \mathrm{L} \mathrm{NAA}$ in combination with $2.0 \mathrm{mg} / \mathrm{L} \mathrm{Kn}$ and $2.0 \mathrm{~g} / \mathrm{L}$ casamino acid (Table 2).

During shoot regeneration, there were several development stages from somatic embryos to regenerating shoots: somatic embryos produced green blots; green blots developed to shoots; calli might produce roots prior to shoot regeneration if NAA concentration was not appropriate to induce shoots; calli with regenerated shoots might go on to produce roots because of the stimulated effect of NAA on root regeneration. To determine the ability of shoot regeneration, the frequencies of green callus forming, shooting, rooting and shooting with roots after 2-month culture on plant regeneration medium were considered as criterion to evaluate plant regeneration ability (Fig. 4).

Conversion to embryogenic callus with green blots was an essential and important step for subsequent shoot regeneration. The frequency of green callus forming of WT ranged 32.7 to $45.8 \%$ on plant regeneration medium with low ( $0-0.5$ $\mathrm{mg} / \mathrm{L})$ or moderate dose $(1.0 \mathrm{mg} / \mathrm{L})$ of NAA, but significantly decreased to $12.2 \%$ under high dose $(1.5 \mathrm{mg} / \mathrm{L})$ of NAA (Fig. 4A). For JS green callus forming, there were some improvements with the addition of NAA with $0.2 \mathrm{mg} / \mathrm{L}$ stimulating the highest frequency of green callus forming (Fig. 4B). Rapid and direct shoot regeneration was highly expected during plant regeneration. The addition of NAA enhanced the ability of shoot regeneration in WT and JS, showing relatively higher frequencies of shooting as compared with that on the medium without NAA (Fig. 4). However, it was known commonly that if roots formed from callus prior to regenerating shoots, shoots were difficult to regenerate successively. So in our study, relatively high shooting frequency and relatively low rooting frequency were required for an efficient regeneration system. The stimulated effect of NAA on rooting was obviously found under 1.0-1.5 mg/L NAA with no variance between WT and JS, showing significantly increase in the frequency of rooting (Fig. 4A, B). The same responses to NAA were obtained from the frequencies of shooting with roots, showing that $0.2-0.5 \mathrm{mg} / \mathrm{L}$ NAA significantly inhibited rooting from regenerated shoots, but $1.5 \mathrm{mg} / \mathrm{L} \mathrm{NAA}$ enhanced 
root regeneration. In conclusion, plant regeneration medium with lower level of NAA $(0.2-0.5 \mathrm{mg} / \mathrm{L})$ was optimal conditions for shoot regeneration, with no variation of genotypes.

\section{Rooting}

Embryogenic callus with regenerated shoots until grown 3-4 $\mathrm{cm}$ in length were transferred to half-strength MS medium for rooting, and $100 \%$ embryogenic calli produced roots within the next following one week (Fig. 1I). The bestrooted plantlets were transferred to soil and grown under greenhouse conditions (Fig. 1J). All regenerated plants showed normal morphology. And they had grown to mature with viable seeds in green house (Fig. 1K). Plantlets which were grown at $33-43^{\circ} \mathrm{N}$ latitude and $124-132^{\circ} \mathrm{E}$ longitude (Chuncheon, Korea) with all-year average temperature of $18^{\circ} \mathrm{C}$ flowered in July.

\section{Discussion}

Somatic embryogenesis may be affected by different combinations of medium, such as minerals, sugar, vitamins and plant growth regulators (Wetherell and Dougall 1976, Kohlenbach 1978, Kamada and Harada 1979, Sharma et al. 2005, Khaleda and Al-Forkan 2006). Amino acids are also found to enhance tissue culture, for example, Morcillo et al. (1999) has reported glutamine and arginine play an important role of the maturation of oil palm somatic embryos (Morcillo et al. 1999); Khaleda and Al-Forkan have reported that proline and casein hydrolysate stimulated callus induction and plant regeneration of five deepwater rice (Khaleda and Al-Forkan 2006). Nitrogen sources, especially organic salts, were widely studied on somatic embryogenesis in many plant species (Wetherell and Dougall 1976, Skokut et al. 1985). In this experiments, amino acids (glycine and proline), 2,4-D, $\mathrm{KNO}_{3}$, explants types, and genotypes were investigated to influence callus induction and shoot regeneration of $L$. chinensis.

For L. chinensis tissue culture, Gao (1982) had reported that modified MS medium with lower ratio of $\mathrm{NH}_{4} / \mathrm{NO}_{3}$ had been found having the highest callus induction and plant regeneration formation. Kim et al. (2005) showed that 2,4-D, the key factor in callus induction, had a significant effect on primary callus induction (Kim et al. 2005). Glutamine (300-500 mg/L) and proline $(500 \mathrm{mg} / \mathrm{L})$ were found to play major roles of the improvement of callus growth status and somatic embryogenesis (Zhang et al. 2007). To determine the optimum culture condition, various conbinations of glycine, proline, 2,4-D and $\mathrm{KNO}_{3}$ in $\mathrm{L}_{9}\left(3^{4}\right)$ orthogonal test were studied.
Medium 6 supplemented with $4.0 \mathrm{mg} / \mathrm{L}$ glycine, $0.3 \mathrm{~g} / \mathrm{L}$ proline, $1.0 \mathrm{mg} / \mathrm{L} 2,4-\mathrm{D}$ and $1.0 \mathrm{~g} / \mathrm{L} \mathrm{KNO}_{3}$ had the highest frequency of primary callus induction using mature seeds as explants (83.3\% and $79.2 \%$ in WT and JS, respectively). Statistically analyses showed that the medium with $0.5 \mathrm{~g} / \mathrm{L}$ proline (Medium 2, 4 and 7) caused a remarkable increase of callus induction in JS; the medium with $4.0 \mathrm{mg} / \mathrm{L}$ glycine (Medium 3, 6 and 9) enhanced relatively high callus induction from mature seeds but not from leaf base segments and root segments. Calli were divided into three types by the growth status, of which $\mathrm{P}$ callus was the preferred callus type for plant regeneration with high growth rates and easy conversion to embryogenic callus, M callus grew slowly and took a long time to finish the conversion to embryogenic callus, and IP callus was difficult to induce shoots or plantlets. Classification of callus type was essential for sequent plant regeneration. It is established that different combinations of auxin and cytokinin play important roles in organogenic callus production, shoot formation and plant regeneration (Rout and Das 1994, Cardona et al. 1997). NAA which has been considered as an important growth factor of plant regeneration, also played an important role on shoot regeneration in this experiments. However, some studies showed that NAA has the effect on root development (Wei et al. 2005). So the effect of NAA required to be investigated for an optimal culture condition of shoot regeneration. Plant regeneration medium without NAA decreased significantly the frequency of green callus forming and shooting, suggesting that the addition of NAA enhanced the ability of conversion to regenerated shoots. When moderate or high dose of NAA (1.0 $-1.5 \mathrm{mg} / \mathrm{L}$ ) was added to plant regeneration medium, most calli induced roots before germination of shoots, which strongly restricted plant regeneration and resulted in low shooting frequency, indicating that high dose of NAA blocked shoot regeneration and promoted germination of roots. JS embryogenic calli showed higher frequency of green callus forming than WT, indicated that JS embryogenic calli had stronger vital force, although plant regeneration frequency of JS was not expectedly higher than that of WT. In conclusion, plant regeneration medium with $0.2-0.5 \mathrm{mg} / \mathrm{L}$ NAA was considered as the preferred culture medium for shoot regeneration in this study. Because we only used $\mathrm{P}$ callus for further shoot regeneration experiments, the large amount of $\mathrm{M}$ and IP callus could not be ignored. How to improve the growth status of M and IP callus and how to quicken the conversion to embryogenic callus would be taken into account in the future.

Improvement of genetic traits of this grass is in the progress (Shu et al. 2005, Wang et al. 2008), but yet little information could be available. In our study, we improved the culture 
conditions by optimizing the compositions of callus induction and regeneration medium through adding certain growth regulators, amino acids and organic nitric salt. An efficient callus induction and plant regeneration system was established for developing an efficient protocol for $L$. chinensis regeneration from mature seeds, leaf base segments and root segments and supplying an option for improving germplasm of this grass.

Acknowledgements This work was supported by Nutraceutical Bio Brain Korea 21 Project Group.

\section{References}

Bai YF, Han XG, Wu JG, Chen ZZ, Li LH (2004) Ecosystem stability and compensatory effects in the Inner Mongolia grassland. Nature 431:181-184

Cardona CA, Duncan RR (1997) Callus induction and high efficiency plant regeneration via somatic embryogenesis in Paspalum. Crop Sci 37:1297-1302

Duncan DB (1955) Multiple range and multiple $F$ tests. Biometrics $11: 1-42$

Gao TS (1982) Induction of callus and regeneration of plantlets from the rhizome explant of Aneurolepidium chinensis. Acta Bot Sin 24: 182-185

Huang XQ, Wei ZM (2004) High-frequency plant regeneration through callus initiation from mature embryos of maize (Zea Mays L.). Plant Cell Rep 22:793-800

Huang ZH, Zhu JM, Mu XJ, Lin JX (2004) Pollen dispersion, pollen viability and pistil receptivity in Leymus chinensis. Ann Bot 93:295-301

Jin H, Plaha P, Park JY, Hong CP, Lee IS, Yang ZH, Jiang GB, Kwak SS, Liu SK, Lee JS, Kim YA, Lim YP (2006) Comparative EST profiles of leaf and root of Leymus chinensis, a xerophilous grass adapted to high $\mathrm{pH}$ sodic soil. Plant Sci 170:1081-1086

Jin H, Kim HR, Plaha P, Liu SK, Park JY, Piao YZ, Yang ZH, Jiang GB, Kwak SS, An G, Son M, Jin YH, Sohn JH, Lim YP (2008) Expression profiling of the genes induced by $\mathrm{Na}_{2} \mathrm{CO}_{3}$ and $\mathrm{NaCl}$ stresses in leaves and roots of Leymus chinensis. Plant Sci 175:784-792

Kamada H, Harada H (1979) Studies on the organogenesis in carrot tissue cultures. II. Effects of amino acids and inorganic nitrogenous compounds on somatic embryogenesis. Z Pflanzenphysiol 91:453-463

Khaleda L, Al-Forkan M (2006) Stimulatory effects of casein hydrolysate and proline in in vitro callus induction and plant regeneration from five deepwater rice (Oryza sativa L.). Biotechnol 5:379-384

Kim MD, Jin H, Park EJ, Kwon SY, Lee HS, Kwak SS (2005) Plant regeneration through somatic embryogenesis of Leymus chinensis Trin. Korean J Plant Biotechnol 32:51-55

Kohlenbach HW (1978) Comparative somatic embryogenesis. In:
Thorpe TA (ed) Frontiers of plant tissue culture, University of Calgary Press, Calgary, Alberta, Canada pp 59-66

Liu GS, Liu JS, Qi DM, Chu CC, Li HJ (2004) Factors affecting plant regeneration from tissue cultures of Chinese leymus (Leymus chinensis). Plant Cell Tissue Organ Cult 76:175-178

Liu GS, Wang EH, Liu J, Qi DM, Li FF (2002) Plant regeneration of Leymus chinensis via in vitro culture. Acta Agrestia Sin 10: 198-202

Morcillo F, Aberlenc-Bertossi F, Noirot M, Hamon S, Duval Y (1999) Differential effects of glutamine and arginine on $7 \mathrm{~S}$ globulin accumulation during the maturation of oil palm somatic embryos. Plant Cell Rep 18:868-872

Murashige T, Skoog F (1962) A revised medium for rapid growth and bioassays with tobacco tissue cultures. Physiol Plant 15 : 473-497

Rout GR, Das P (1994) Somatic embryogenesis and in vitro flowering of 3 species of bamboo. Plant Cell Rep 13:683-686

Sharma VK, Hänsch R, Mendel RR, Schulze J (2005) Mature embryo axis-based high frequency somatic embryogenesis and plant regeneration from multiple cultivars of barley (Hordeum vulgare L.). J Exp Bot 56:1913-1922

Shu QY, Liu GS, Xu SX, Li XF, Li HJ (2005) Genetic transformation of Leymus chinensis with the PAT gene through microprojectile bombardment to improve resistance to the herbicide Basta. Plant Cell Rep 24:36-44

Skokut TA, Manchester J, Schaefer J (1985) Regeneration in alfalfa tissue culture: stimulation of somatic embryo production by amino acids and N-15 NMR determination of nitrogen utilization. Plant Physiol 79:579-583

Wang YS, Xue M, Zheng XH, Ji BM, Du R, Wang YF (2005) Effects of environmental factors on $\mathrm{N}_{2} \mathrm{O}$ emission from and $\mathrm{CH}_{4}$ uptake by the typical grasslands in the Inner Mongolia. Chemosphere 58:205-215

Wang LJ, Li XF, Chen SY (2008) Enhanced drought tolerance in transgenic Leymus chinensis plants with constitutively expressed wheat TaLEA3. Biotechnol Lett. doi: 10.1007/s10529008-9864-5

Wang ML (1998) A study on seed production of Aneurolepidium chinensis. Grassland China 20:18-20

Wei Q, Hu GF, Li FL, Hu BZ (2005) Study on callus inducement and plant regeneration in seeds of Aneurolepidium chinensis (Trin.) Kitag. J Northeast Agric Univ 36:41-44

Wetherell DF, Dougall DK (1976) Sources of nitrogen supporting growth and embryogenesis in cultured wild carrot tissue. Physiol Plant 37:97-103

Xu ZZ, Zhou GS (2005) Effects of soil moisture on gas exchange, partitioning of fed ${ }^{14} \mathrm{CO}_{2}$ and stable carbon isotope composition $\left(\delta^{13} \mathrm{C}\right)$ of Leymus chinensis under two different diurnal temperature variations. J Agron Crop Sci 191:27-34

Zhang Y, Li XF, Liu GS, Chen YF (2007) Regulation of callus status of Leymus chinensis. J Northwest A\&F Univ (Nat Sci Ed) $35: 111-114$

Zhang WD, Liu GS, Liu J, Liu F, Qi DM, Li FF, Dong GJ, Zhao JJ (2002) A preliminary study on self-incompatibility of Leymus chinensis. Acta Bot Boreal-Occident Sin 10:287-292 